\title{
Some Missing Tools For Business Statistics: How To Teach Them
}

Robert T. Amsden, (E-mail: Amsden@udayton.edu), University of Dayton Davida M. Amsden, (E-mail: Amsden@udayton.edu), University of Dayton

\begin{abstract}
Missing from business statistics texts are several tools, but how does one add additional material to an already crammed, required course? We briefly describe these tools. This paper explains how to incorporate these missing tools in a time-efficient manner. We show how to teach them in a way that helps students to: (1) learn basic statistical concepts, (2) distinguish the two kinds of variation, (3) find structure within data, and (4) set priorities on problems. By learning these four concepts at the beginning of a statistics course, students will then have a solid, practical foundation for learning the remaining statistical material to be covered.
\end{abstract}

\section{Introduction}

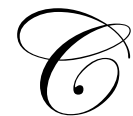

urrently, business statistics are viewed from a narrow academic perspective. Academicians often regard statistics merely as one tool among many for use in business. The authors of college textbooks present the concepts as though business statistics should be taught in the same manner as theoretical, mathematical statistics, without considering the requirements of business. This view of business statistics needs to be considerably broadened.

Students are also affected by this academic approach to business statistics. Because statistical concepts are presented in a piecemeal fashion, there is often little to hold the pieces together in any coherent way until students encounter more sophisticated topics such as confidence intervals. Secondly the traditional treatment of statistics ignores the two distinct types of variation that can be present in data: random variation and non-random variation. Our students need to learn to recognize these two kinds of data and then to think statistically every time they encounter data. Additionally, students need to learn statistics from a business perspective because they will be working in business. This paper suggests some ways business statistics can be taught from a broader perspective that will enable students to function more effectively in business.

\section{Current Situation Vis-à-vis the Teaching of Business Statistics}

It may help to clarify the current situation if we briefly review four typical business statistics texts. These books cover much of the same material in much the same order: introduction to statistics followed by types of variables and kinds of data, how to plot distributional data, measures of center and variation, probability, distributions, estimation, before bringing in the more advanced concepts of tests of hypotheses, analysis of variance, etc. Table 1 [A Typical Introductory Sequence to Business Statistics] illustrates the sequence of topics for Douglas Lind, et al. (Lind, Marchal, \& Mason, Statistical Techniques in Business \& Economics).

The text by David M. Levine et al. (Levine, Berenson, \& Stephan, Statistics for Managers Using Microsoft ${ }^{\circledR}$ Excel) utilizes the same sequence of topics, although this text includes some notable differences. Enumerative versus analytical studies as well as ethical issues are discussed in the first chapter; and numerous applications using Excel are provided. The book by Patrick Shannon, et al. (Shannon, Groebner, Fry, \& Smith, A Course in Business Statistics) also follows much the same outline as Lind et al.'s text. This text briefly introduces survey sampling in Chapter 1; the authors have interspersed some of the "quality" tools - check sheets, histograms, and Pareto charts.

Readers with comments or questions are encouraged to contact the authors via email. 
Keller and Warrack's book (Keller \& Warrack, Statistics for Management and Economics) uses a similar format, but they include a chapter on graphical excellence and graphical deception as well as one on statistical process control - at the end of the book.

Table 1 A Typical Introductory Sequence to Business Statistics

\begin{tabular}{|c|l|}
\hline Chapter & Topics \\
\hline $\mathbf{1 .}$ & $\begin{array}{l}\text { Descriptive versus inferential statistics } \\
\text { Types of variables } \\
\text { Types of data } \\
\text { Uses \& abuses of statistics } \\
\text { Computer applications }\end{array}$ \\
\hline $\mathbf{2 .}$ & $\begin{array}{l}\text { Frequency distributions } \\
\text { Relative frequency distributions } \\
\text { Software example } \\
\text { Stem \& leaf plots } \\
\text { Graphs of frequency distributions } \\
\text { Misleading graphs, }\end{array}$ \\
\hline $\mathbf{3 .}$ & Measures of central tendency \\
\hline $\mathbf{4 .}$ & $\begin{array}{l}\text { Measures of variation } \\
\text { Chebyshev's (Tchebysheff's) theorem } \\
\text { Empirical rule } \\
\text { Skewness }\end{array}$ \\
\hline $\mathbf{5 .}$ & Probability \\
\hline $\mathbf{6 .}$ & Discrete probability distributions \\
\hline $\mathbf{7 .}$ & Normal probability distribution \\
\hline $\mathbf{8 .}$ & $\begin{array}{l}\text { Sampling methods including a brief description of survey sampling } \\
\text { Central limit theorem }\end{array}$ \\
\hline $\mathbf{9 .}$ & $\begin{array}{l}\text { Estimation } \\
\text { Confidence intervals }\end{array}$ \\
\hline $\mathbf{1 0 .}$ & One sample tests of hypotheses \\
\hline $\mathbf{1 1 .}$ & Etc. \\
\hline & \\
\hline
\end{tabular}

Table 2 Components of a Confidence Interval

\begin{tabular}{|l|l|}
\hline Component & \multicolumn{1}{c|}{ Description } \\
\hline $\mathrm{P}$ & $\begin{array}{l}\text { Confidence, a concept building on the student's prior understand- } \\
\text { ing of probability }\end{array}$ \\
\hline $\mathrm{x}$-bar & $\begin{array}{l}\text { Measure of central tendency, a statistic; based on a random sam- } \\
\text { ple }\end{array}$ \\
\hline 1.96 & Value obtained from the normal probability distribution \\
\hline sigma & A measure of variation, a parameter \\
\hline $\mathrm{n}$ & The sample size \\
\hline $\mathrm{mu}$ & The population mean, a parameter \\
\hline 0.95 & The confidence level \\
\hline
\end{tabular}
of building materials to the site: bricks, concrete blocks, sand and gravel for concrete, lumber, plywood, roofing, and so on. To the casual observer, these materials appear disorganized and unsightly. It is only after some time when the shell of the house has taken shape that the beauty of the home begins to be discernible to the passerby. Similarly, when traditional college-level texts introduce the various foundational elements of statistics as separate pieces, as building blocks, these important concepts often appear irrelevant and/or boring to students because practical, integrative business applications are usually lacking.

This traditional approach has several flaws. First, as we have already observed, the treatment of the foundational statistical concepts tends to be rather disjointed. Consequently, students do not see how these basic concepts are connected until they study the normal probability statement and confidence intervals. For example, the confidence interval for the mean of a normal population, mu, contains a number of seemingly disparate pieces that the student will have studied in the first third of the course.

$\mathrm{P}[\mathrm{x}-\mathrm{bar}-1.96$ sigma/square root $(\mathrm{n})<\mathrm{mu}<\mathrm{x}$-bar $+1.96 \mathrm{sigma} / \mathrm{square}$ root $(\mathrm{n})]=$ 0.95

We list the individual components of the confidence interval in Table 2 [Components of a Confidence Interval].

We have found that beginning statistics students have little "Velcro" on which to stick these concepts. Students don't see how the pieces relate to one another or how to connect successive statistical concepts and techniques, until they encounter normal probability, confidence intervals, and tests of hypotheses. The situation is analogous to constructing a home. The general contractor brings a variety

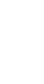

(n)


Secondly, the traditional treatment introduces a serious misunderstanding of real business problems. It would appear that business statistics developed out of a mathematical approach and, therefore, traditional business texts tend to put forth "pure" statistical theory. The theory holds that data have randomness in them, the kind of randomness that can be described by probability. The theory, as theory, is correct - it is randomness that gives rise to probabilities; it is randomness that is the basis of the binomial probability distribution and the normal probability distribution. But the application is incorrect. In reality businesses processes - whether manufacturing or service nearly always consist of two kinds of variation: random variation mixed together with non-random variation, unless statistical measures have deliberately been taken. Most texts unwittingly teach that business processes usually contain only randomness. Consequently the student comes to expect only randomness in the data he/she will handle and that all he/she will have to do is determine which probability distribution applies

Third, traditional presentation of statistics provides no comprehensive analytical business approach. The typical text may give pieces of such a comprehensive methodology, but usually stops short of developing a total system. What is presented is done along the lines of mathematical statistics. Instead of a teaching/learning model that builds little by little where the parts fit together only as mathematical logic dictates, business requires a different methodology.

\section{Recommendations}

In order to prepare students better for the world of business, we recommend the teaching of statistics from a perspective taken from the practice of business, not developed from a mathematical viewpoint. Our recommendation applies primarily to the first part of the business statistics course with a focus on three areas:

1. The two kinds of variation usually present in business processes

2. Helping students get a "feel" for statistical concepts before learning rigorous theory

3. A coherent comprehensive analytical business framework.

The result is that students learn to think statistically about all data they encounter, thus enabling them to understand the data. They learn to look for the two kinds of variation in every business process they study. Early in the statistics course, they develop "Velcro" to which they can attach statistical concepts throughout the remainder of the course and so become interested in statistics. They do not learn just about randomness, but they also get a feel for the two kinds of variation and for hidden structure within data. In short, they learn to look at statistics from a business perspective. Consequently, they are better able to function in business.

We will now examine our recommendations in more detail.

\section{Two Kinds of Variation}

In studying business processes, we nearly always find two kinds of variation, random and non-random, intermixed with but two exceptions. The first is a business process that has been, and continues to be, carefully managed in order to remove non-random variation. The other is the rare process that, although management has not specifically worked to remove non-random behavior, appears to exhibit only randomness. Random variation arises from an uncountable series of causes. This type of variation is inherent to the system itself. It is unpredictable in that one cannot predict the next observation mathematically. One can only describe the observation using probability. Other terms for randomness include: common causes of variation, system causes of variation, inherent variation, and noise.

Non-random variation in a process may have some predictable patterns, for example, a sudden change, a cycle, a trend, or a saw tooth through time. We may refer to non-randomness as assignable causes of variation, special cause of variation, predictable variation, and a signal. The term "assignable causes of variation" is used because often the cause can be identified, that is, a specific reason for the variation can be assigned.

Students need to realize from day one of a statistics course that both types of variation are endemic to busi- 
ness processes. They need to learn to be on the watch for non-random behaviors in any process they decide to study. This is why we begin our statistics course with the Shewhart Bowl.

\section{A Teaching Tool - The Shewhart Bowl}

Walter A. Shewhart developed the Shewhart Bowl as a teaching device to use in his seminars (Shewhart, page 165). The bowl contains 998 small disks. On each disk is a three digit number running from -3.00 to +3.00 . The frequencies of the numbers, hence of the disks, are determined by the normal probability distribution. This means there is only one disk at -3.00 while there are many at 0.00 . In order to ease data collection, we have modified the numbers so that they run from 00 to 60 . We have a bowl of 998 small disks with an appropriate two-digit number on each, but with frequencies closely matching the normal distribution.

We have several teaching objectives in mind when using our modified version of the Shewhart Bowl (simply called the Shewhart Bowl). First, we want the students to experience, to get a "feel for" both randomness and non-randomness. Second, students need to be able to distinguish between the two types of variation. Finally, the Shewhart Bowl is a reference point; the student can always refer back to it when analyzing business process data for random and non-random behaviors later in the course.

In teaching the concepts of randomness and non-randomness, we define these two terms for the students and give the alternative names before we start using the Bowl. We explain that a business process or system is designed and built under the direction of management. The system encompasses materials from suppliers, machinery/equipment, training, the environment, the methods used, and others. Although each of these elements of the system is under management's jurisdiction, they all contribute to the variation in the product/service output of the process. Because system causes of variation are under management's jurisdiction, we say that management is responsible for the random variation of the process, not the worker.

Then we explain that non-random variation is usually the result of discernible causes. Possible causes are a change in materials from the supplier, a change in the way the machine/equipment is running, a change in the method used, or any of a myriad of other causes. Since these causes are usually discernible, the associate running the process may be given the responsibility for finding when they occur, for identifying their specific cause, and for removing them.

Now we are ready to use the Bowl. We ask our students to collect the data from the Shewhart Bowl themselves, so the exercise is interactive. We instruct a student to take the Bowl, shake it well, then to reach in and, without looking at the disks, take out five. He/she reads the numbers out loud and we record them. Then the next student goes through the same process and draws a second sample of five. We continue in this manner until we have ten or so samples, each of size five. Table 1 [Shewhart Bowl Samples: Only Random Variation] illustrates the data.

We ask the class a series of questions:

1. As the students take the samples, we ask whether anyone can predict the next sample?

- $\quad$ In what sense is the answer "Yes?"

- $\quad$ In what sense is it "No?"

- In what sense is this a predictable, stable process? Why?

2. Who is in control of this variation

- $\quad$ You, the operator of the process?

- Management who developed it, who gave you the method of selecting the sample, and who watched to make sure that you followed directions?

- Why?

3. Should the operator be blamed/held accountable for random variation?

- Have you, the student, ever been blamed/held accountable for random variation? 
Table 1 Shewhart Bowl Samples: Only Random Variation

\begin{tabular}{|c|c|c|c|c|c|c|c|c|c|c|}
\hline Sample \# & $\mathbf{1}$ & $\mathbf{2}$ & $\mathbf{3}$ & $\mathbf{4}$ & $\mathbf{5}$ & $\mathbf{6}$ & $\mathbf{7}$ & $\mathbf{8}$ & $\mathbf{9}$ & $\mathbf{1 0}$ \\
\hline & 27 & 38 & 43 & 12 & 50 & 43 & 37 & 23 & 29 & 13 \\
\hline & 30 & 41 & 18 & 32 & 39 & 28 & 26 & 24 & 35 & 35 \\
\hline & 25 & 17 & 30 & 27 & 41 & 35 & 19 & 33 & 41 & 29 \\
\hline & 45 & 46 & 27 & 37 & 43 & 45 & 37 & 18 & 27 & 32 \\
\hline & 33 & 39 & 30 & 20 & 32 & 4 & 40 & 21 & 36 & 36 \\
\hline Mean & $\mathbf{3 2 . 0}$ & $\mathbf{3 6 . 2}$ & $\mathbf{2 9 . 6}$ & $\mathbf{2 5 . 6}$ & $\mathbf{4 1 . 0}$ & $\mathbf{3 1 . 0}$ & $\mathbf{3 1 . 8}$ & $\mathbf{2 3 . 8}$ & $\mathbf{3 3 . 6}$ & $\mathbf{2 9 . 0}$ \\
\hline
\end{tabular}

These questions steer the discussion and cause students to wrestle with the impossibility of predicting the individual observations in each sample of five. The results are random. However, since all 50 observations lie between 4 and 50 inclusive, there is a certain degree of predictability: we can state that most future observations will lie between 4 and 50 as long as only random variation continues to occur. We point out that, if 4 to 50 represent acceptable limits to the customer, then this process will continue to yield an output that usually meets the customer's requirements - a very important characteristic in business. Because the students have collected the data, they have experienced what randomness feels like. Sometimes students are frustrated with trying to control the randomness. They begin to understand that is fruitless for management to insist that process operators prevent the random behavior built into the system itself. They can experience how an employee feels when management puts pressure on them to control the random variation. The exercise is clearly and forcefully tied into what happens in the operations of a company.

Table 2 Random and Non-random Variation

\begin{tabular}{|l|c|c|c|c|c|c|c|c|c|c|c|c|c|}
\hline $\begin{array}{l}\text { Sample } \\
\text { \# }\end{array}$ & $\mathbf{1}$ & $\mathbf{2}$ & $\mathbf{3}$ & $\mathbf{4}$ & $\mathbf{5}$ & $\mathbf{6}$ & $\mathbf{7}$ & $\mathbf{8}$ & $\mathbf{9}$ & $\mathbf{1 0}$ & $\mathbf{1 1}$ & $\mathbf{1 2}$ & $\mathbf{1 3}$ \\
\hline & 27 & 38 & 43 & 12 & 50 & 43 & 37 & 23 & 29 & 13 & 63 & 76 & 71 \\
& 30 & 41 & 18 & 32 & 39 & 28 & 26 & 24 & 35 & 35 & 85 & 79 & 98 \\
\hline & 25 & 17 & 30 & 27 & 41 & 35 & 19 & 33 & 41 & 29 & 79 & 85 & 99 \\
\hline & 45 & 46 & 27 & 37 & 43 & 45 & 37 & 18 & 27 & 32 & 82 & 75 & 63 \\
\hline & 33 & 39 & 30 & 20 & 32 & 4 & 40 & 21 & 36 & 36 & 86 & 66 & 68 \\
\hline Mean & $\mathbf{3 2 . 0}$ & $\mathbf{3 6 . 2}$ & $\mathbf{2 9 . 6}$ & $\mathbf{2 5 . 6}$ & $\mathbf{4 1 . 0}$ & $\mathbf{3 1 . 0}$ & $\mathbf{3 1 . 8}$ & $\mathbf{2 3 . 8}$ & $\mathbf{3 3 . 6}$ & $\mathbf{2 9 . 0}$ & $\mathbf{7 9 . 0}$ & $\mathbf{7 6 . 2}$ & $\mathbf{7 9 . 8}$ \\
\hline
\end{tabular}

To illustrate non-random behavior, we make a few adjustments to the Shewhart Bowl. The students take three additional samples of five each, \# 11, 12, and 13. But this time they are to add 50 units to each observation. Table 2 [Random and Non-random Variation] illustrates what we find.

Now we ask a new series of questions:

4. As soon as they take sample \#11 and the results are recorded, we ask: "Did you see any non-random behavior?"

- $\quad$ How much did the process "jump?"

- $\quad$ Once students see how much the process jumped, we ask where do they think the next sample, \#12, will be? 
- We explain that this jump is the result of a special cause of variation, a non-random behavior. Can anyone predict the next sample, \#12? How well?

5. After taking the next two samples, \#12 and \#13, the question is

- In what sense is the whole process, from sample \#1 through sample \#13 representative of a non-predictable process? Non-stable?

- Why?

6. Should the operator be blamed/held accountable for non-random variation?

- Have you, the student, ever been blamed/held accountable for non-random variation?

7. Who in the company has the first opportunity to find the jump in the process?

- What reasonable responsibility could this person exercise?

- What would management have to do in order for this person to exercise this responsibility?

Working through this exercise and asking these questions push the students to think through several things. Now they are experiencing non-random behavior and so get a feel for it. They begin to be able to distinguish it from random behavior. Question "5" asks them to be aware of the distinction between a purely random process and one exhibiting both random and non-random behaviors. They see that a random process is predictable within limits, whereas a process containing a mix of the two kinds of variation is not. We explain that usually these non-random behaviors are unexpected. When they occur is not predictable and the extent or size of them is also unknown. Consequently, such unpredictable, non-random behavior means the company has no ability to predict the future characteristics of the process. This translates into trouble with the customer.

Lastly, we consider who has the first chance to observe the non-random behavior. We point out that this is critical for quick control of the process. We briefly discuss the responsibilities the operator could exercise given appropriate management support. Again, the entire exercise puts the random and non-random behavior into the context of business.

\section{Further uses of the Shewhart Bowl}

We also use the Shewhart Bowl as a reference point throughout the remainder of the course. For example, when we introduce the binomial probability distribution, we examine some manufacturing process data to see whether they meet the conditions of the binomial. We construct a control chart to test whether the probability remains constant throughout the time period. If the control chart shows that the process has non-random variation, we explain why the binomial does not apply. We tie this back to the Shewhart Bowl; just as the adjusted Bowl data clearly demonstrated non-random behavior, so points outside the control chart limits for this manufacturing process are also exhibiting non-random behavior. In tests of hypotheses, we point out that, if the null hypothesis is true, any variation in the data is strictly random, as in our first exercise with the Shewhart Bowl. The alternative hypothesis, on the other hand, depicts a special cause, something which is not random. Because students have seen how the process was distorted when we introduced the special causes to the Shewhart Bowl data, they find it easier to understand that the alternative hypothesis represents non-random behavior.

\section{Another Teaching Tool - The X-bar, R Control Chart}

A second statistical tool we use very early in the course is the $\mathrm{x}$-bar, $\mathrm{R}$ control chart. The data for the chart comes from the first ten samples from the Shewhart Bowl along with the adjusted Shewhart Bowl data. We have several teaching objectives for introducing the control chart. Students learn a technique that both visually differentiates random from non-random behavior and signals when non-random behavior occurs. The control chart illustrates simple measures of center and variation as well as statistical limits. Students learn that business decisions can be made based on an objective quantitative technique.

We prepare the control chart in class as follows. First we write the 10 samples from the Shewhart Bowl on an x-bar, R control chart form. Figure 1 [X-bar, R Control Chart for the Shewhart Bowl Samples: Only Random 
Variation] shows the data at the top of the completed control chart.

Then we show the class how to calculate the $\mathrm{x}$-bar and the range (R) for the first sample. Next we assign different groups in the class to calculate the $\mathrm{x}$-bars and $\mathrm{R}$ 's for the remaining nine samples. We write the results on the form. Turning to the back of the ASQ (American Society for Quality) x-bar, R control chart form, we work together to calculate the overall mean and the overall range. (See Figure 2. Calculations for the X-bar, R Control Chart; Only Random Variation.) We explain that good practice determines the upper and lower control limits for the ranges first. We plot those limits on the front side of the chart and examine the ranges to see whether they are in-statistical-control. In this example, all the ranges are within the control limits, so we can proceed with the calculation of limits for the $\mathrm{x}$-bars.

When we plot the calculated limits for the $\mathrm{x}$-bars on the control chart, we see that all the $\mathrm{x}$-bars are within their control limits as well.

At this point we raise the following series of questions.

1. Does the control chart show any non-random behavior?

2. Should the control chart exhibit non-random behavior?

3. Why or why not?

4. What do you already know about the samples taken from the Shewhart Bowl?

5. Why do we plot the control limits for the ranges first?

6. Could the person operating the process use a control chart to monitor process behavior?

After the students have grappled with these questions, we add the three samples of adjusted data. (See Figure 3, X-bar, R Control Chart: Random and Non-random Variation.) We calculate the x-bars and ranges.

Working through the control chart and questions begins to ameliorate several of the criticisms we have with the way business statistics is taught. First, the $\mathrm{x}$-bar, $\mathrm{R}$ control chart teaches students a graphic way to recognize the two kinds of variation. They see for themselves how the two types of variation affect processes and that it is important to have the means for telling which type is at work. Helping to take the samples and develop the chart gives students hands-on experience with a practical quantitative tool. Students learn some foundational statistical concepts, such as the average as a measure of central tendency, in the practical context of the control chart. In discussing who has the first opportunity to observe any non-random behavior, students see that this is critical for quick control of the process. We briefly discuss the responsibilities the operator could exercise given appropriate management support. We find that this exercise links learning statistical concepts into an integrative framework and shows how they fit in the business context. 
Figure 1, X-bar, R Control Chart for the Shewhart Bowl Samples: Only Random Variation

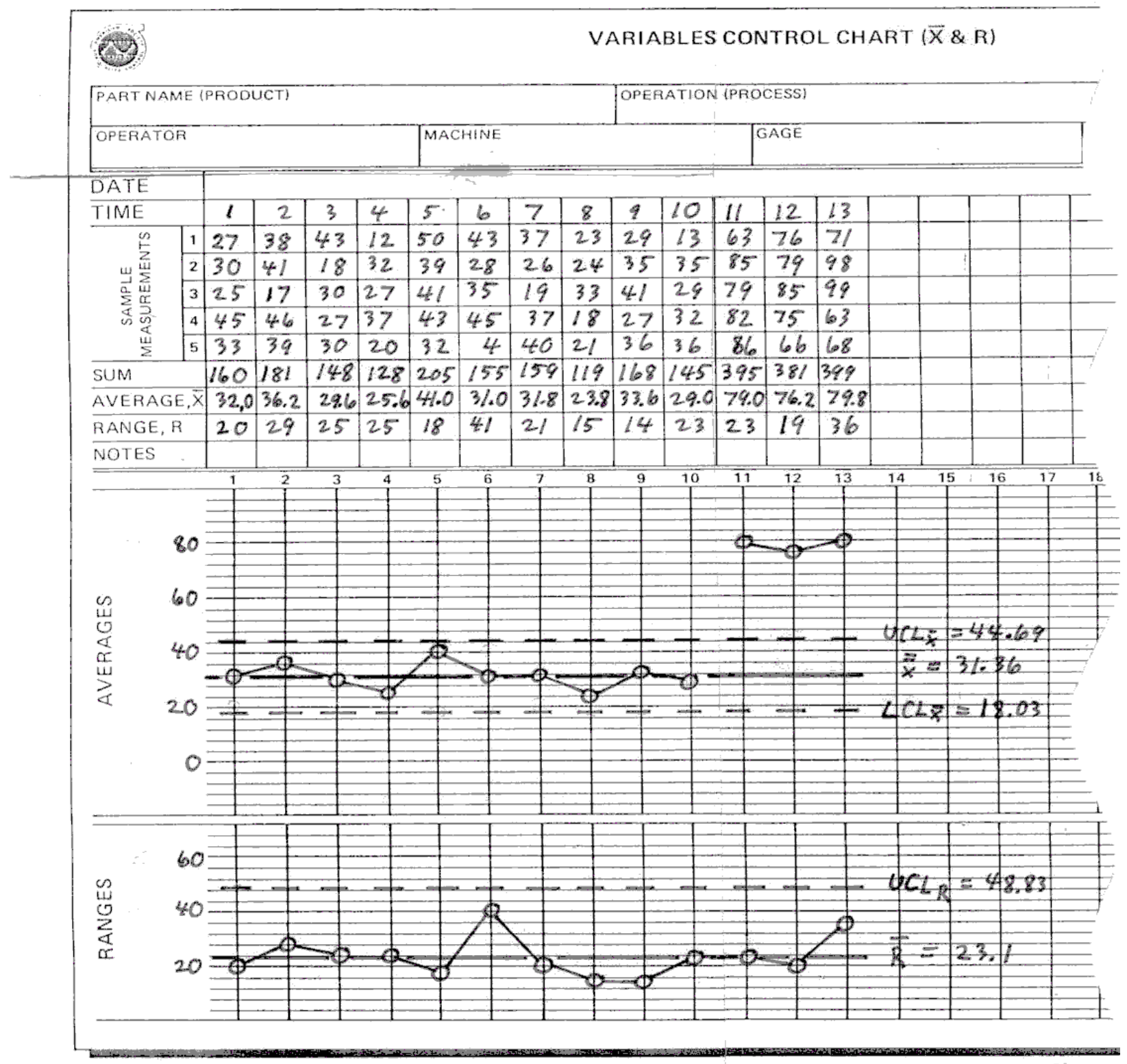

Copyright (c) American Society for Quality Control. 
Figure 2 Calculations for the X-bar, R Control Chart: Only Random Variation.

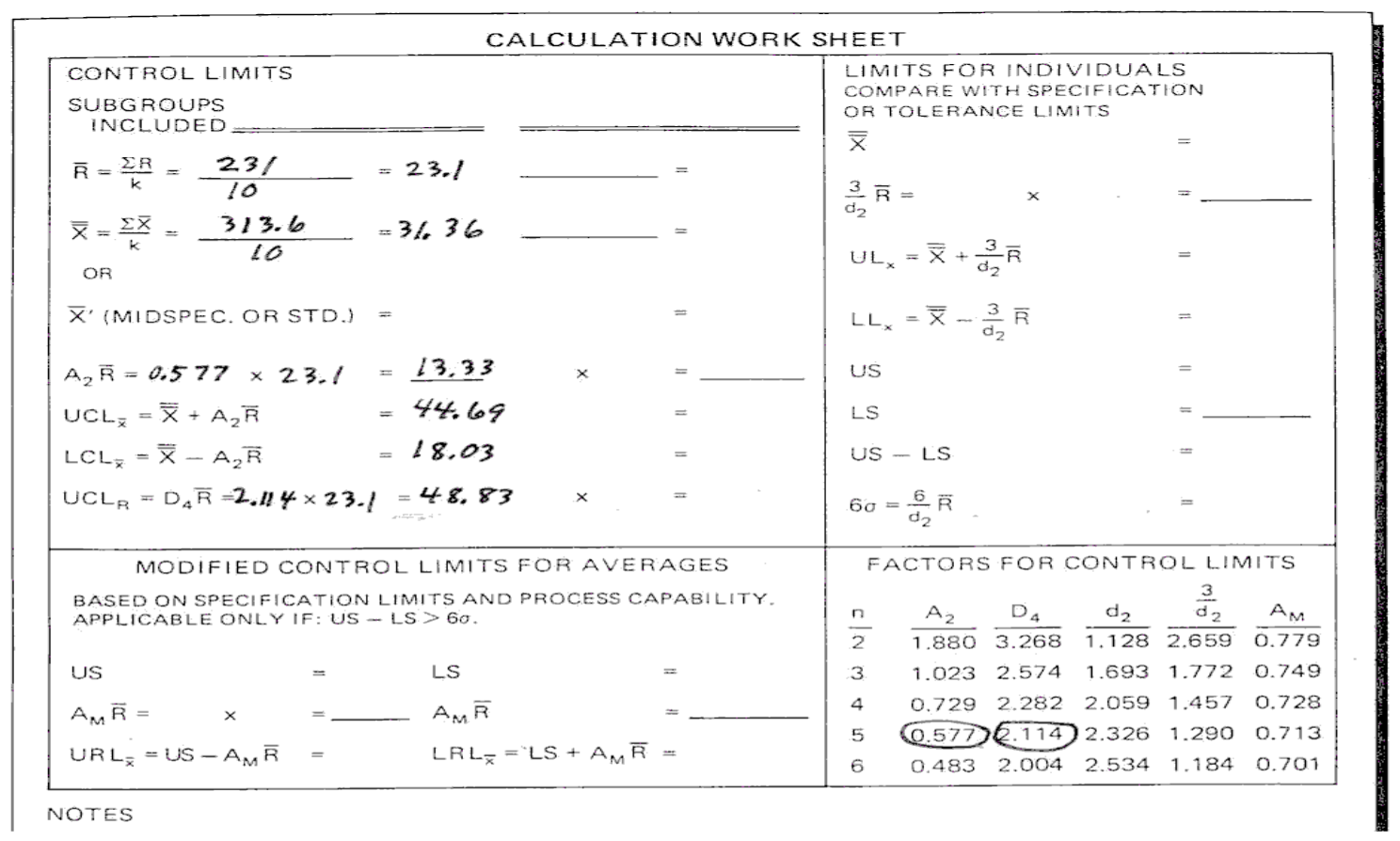

The following questions analyze the completed figure (See Figure 3):

5. Does the control chart now reveal any non-random behavior?

6. Should the control chart exhibit non-random behavior?

- Why or why not?

- What do you already know about the samples taken from the adjusted Shewhart Bowl when combined with the original Shewhart Bowl data?

7. What specifically do you see on the control chart that demonstrates the occurrence of non-random behavior?

- $\quad$ Since we plot control chart data sequentially through time, would this characteristic of control charts provide us with a signal for when non-random behavior occurs?

- $\quad$ Are there other types of non-random behavior which the control chart would not detect?

- How could the person operating a business process utilize this feature of control charts? 
Figure 3, X-bar, R Control Chart: Random and Non-random Variation.

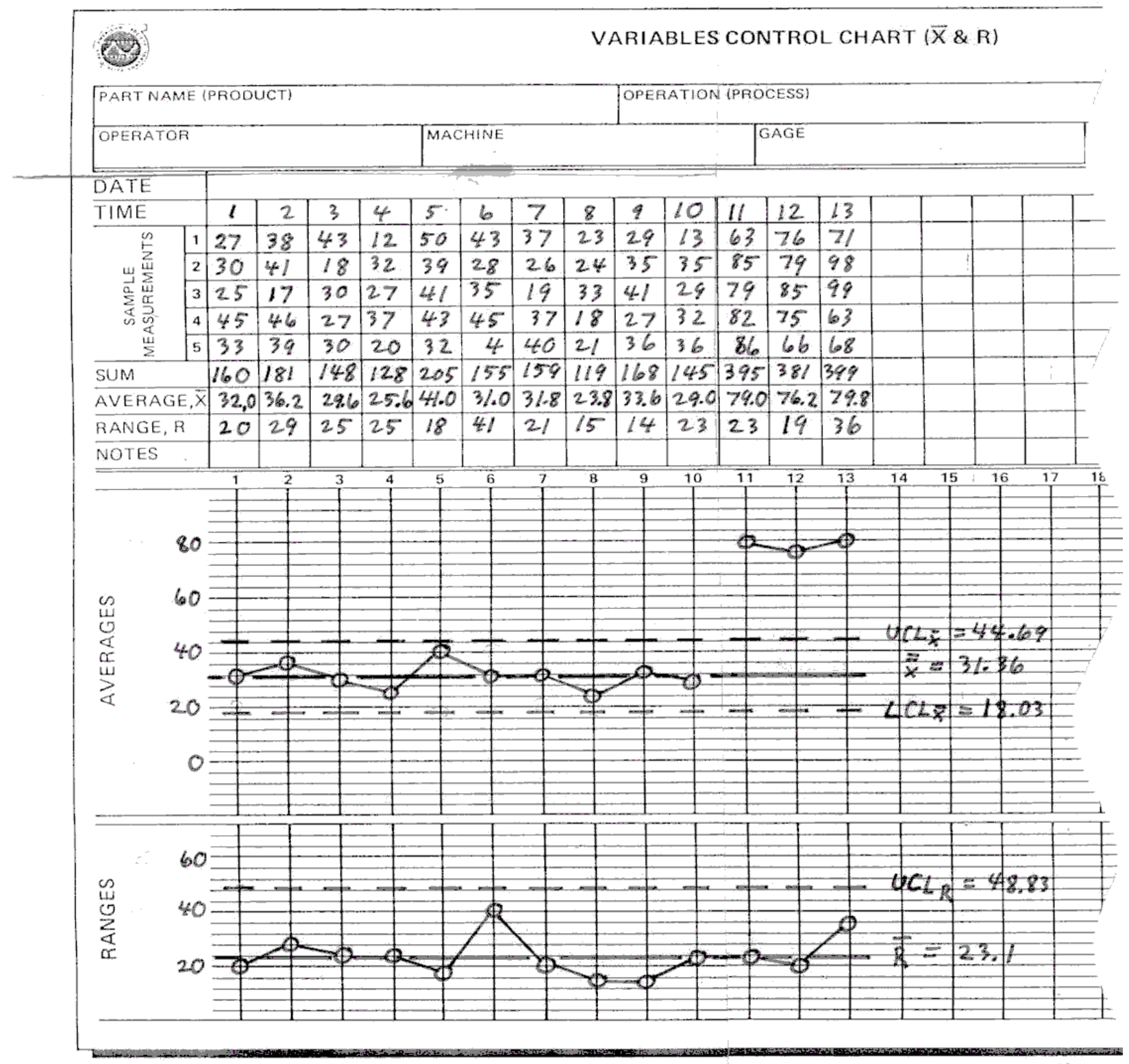

Copyright (c) American Society for Quality Control.

\section{A Comprehensive Business Analytical Framework}

A further important topic we introduce early in the course is the NPDCA model of business decisionmaking. This gives the student a comprehensive business analytical framework that many excellent companies are currently using. We will now describe the model much as we do for our students. The basic components are Need, Plan, Do, Check, and Act. 
Need. The process for making a business decision starts with the perception that something needs to change or improve. As Dr. Joseph Juran long ago observed, management does nothing unless there is proof of need._[Reference: Juran, J.M., Management of Quality Control, 1967 Course Notes, Visual Aid \#21; also, Juran, J.M., And Gryna, Frank M., Jr., Quality Planning and Analysis, $2^{\text {nd }}$ ed., McGraw-Hill Book Co., NY, 1980, PP. 100-101, 127-128]

Plan. is development of theory and ways to test the theory through one or more experiments. In the Plan stage we observe the process. Various tools are available to help. The process flow chart graphically describes the process. We brainstorm or use storyboarding to collect theories about the process. The Cause \& Effect Diagram shows relationships of these theories. Pareto analysis can help establish priorities with respect to the need. Check sheets provide a way to display various structures in the data, both random and non-random. Matrix analysis forms reveal non-random structures in the data. These and others tools help us to hone our theories about the process.

Do. is the execution of the experiment(s). The experiment may be a trial run in operations, or marketing, or finance or in the laboratory. Sometimes Do is a statistically designed experiment.

Check. is the interpretation of the data collected from the Do stage. For example, this may be a computer run statistical analysis or a simple frequency histogram.

Act/Standardize. is where we evaluate how well the experiment(s) validate the theories we have been testing. If the experiment does validate our theory, we should take measures to integrate the knowledge we have gained into the learning of the organization. That is, we need to incorporate any successful solutions by instituting procedures or policies to ensure the solution stays in place. This is standardization.

But sometimes our experiments disprove, or inadequately explain, our theories. In that case we act by returning to plan, revising the theory based on what we have learned from the "failure," and repeating the NPDCA loop.

To help the students see how the NPDCA model works, particular tools apply, and statistical concepts fit into the model, we teach a case study. We will present the case in the NPDCA framework as we do in class.

Need. A manufacturing process producing polyurethane foam seat cushions for cars was running at a rate of nearly $10 \%$ defective product. Management decided the process had to be improved.

Plan. Management appointed a team to work on the problem. The team investigated the kinds of defects using Pareto Analysis. They found that most of the defects, about 95\%, came from unwanted holes in the cushions. They brainstormed for theories for why the holes were occurring. One theory they decided to test was that the temperature during the curing process needed to be carefully controlled. So they set up an experiment where they could vary the temperature to see how many holes occur as a function of temperature.

Do. The team ran the experiment and collected data.

Check. The team organized the data onto an easily readable graph. The graph revealed an optimal temperature range for the process existed.

Act/Standardize. The team wrote out new instructions for the cure process and instructed operating people how to follow the new method. They also did follow-on Pareto analysis to check the effectiveness of their results. Since a certain percentage of defects were still present, they went back to Plan and refined their theories.

As we present this case, we discuss appropriate tools used in the steps. For example, we work with data to show the before and after situation. We may also have students prepare percent defective control charts. 


\section{Missing Tools}

Table 3, [List of Missing Tools] lists many of the tools we believe should be included in the standard business statistics course. Those marked with an asterisk (*) are ones commonly not included.

Table 3 List of Missing Tools

\begin{tabular}{|c|c|}
\hline Tools & Tools (continued) \\
\hline Preliminary tools & Preliminary tools (continued) \\
\hline Visualization of the process & Run charts * \\
\hline Process flowcharting * & Control charts * \\
\hline Prioritization of theories & x-bar, R control charts * \\
\hline Pareto analysis * & $\mathrm{x}, \mathrm{R}$ control charts $*$ \\
\hline Collection, and determining relationships of theories & p control charts * \\
\hline Brainstorming $*$ & c control charts $*$ \\
\hline Story boarding * & Process capability analysis * \\
\hline Cause \& effect diagrams * & Histogram method * \\
\hline Data collection & x-bar, R control chart method * \\
\hline Check sheets * & Normal probability plot method $*$ \\
\hline Matrix analysis forms * & Indices $*$ \\
\hline Ways to present data & $\mathrm{C}_{\mathrm{p}}$ index $*$ \\
\hline Graphs & $\mathrm{C}_{\mathrm{pk}}$ index $*$ \\
\hline Frequency histograms & Advanced tools \\
\hline Scatter diagrams & Tests of hypotheses \\
\hline Other ways to analyze data & $\mathrm{F}$ test \\
\hline Stratification * & Anova \\
\hline & Etc. \\
\hline
\end{tabular}

\section{Summary}

Most current business statistics textbooks present statistics in a piecemeal manner, making it hard for the student to integrate the material. The texts inadvertently teach the student that business processes exhibit only random behavior. They fail to provide an overall business analytical framework.

We recommend teaching business statistics from a business perspective. This includes distinguishing between random and non-random variation that business processes nearly always exhibit. Students study the two types of variation, utilize some easy-to-use statistical tools early in the course, learn a comprehensive business analytical approach, and thereby get a feel for statistical concepts. This teaching method provides the students with Velcro on which to attach further statistical concepts.

We teach the two types of variation, random and non-random, by using the Shewhart Bowl. This allows us to ask some very pointed questions about basic statistical concepts. The exercise becomes a reference point to which much of the remainder of the course can be related. The $\mathrm{x}$-bar, $\mathrm{R}$ control chart offers the students an objective, quantitative technique for distinguishing certain kinds of non-random behavior from random. The chart also gives them an introduction to a variety of statistical concepts before they encounter rigorous theory. We also teach a comprehensive business analytical framework, the NPDCA, Need, Plan, Do, Check, and Act/Standardize, model. To illustrate this framework, we use a manufacturing case study. We also list a variety of statistical, and some notso-statistical, tools which are used in the NPDCA analytical approach.

The inclusion of these topics in a statistics course begins to move student learning more towards the needs of business and away from a purely math-stat approach. 


\section{References and Endnotes}

1. Lind, Douglas A., Marchal, William G., \& Mason, Robert D., Statistical Techniques in Business \& Economics, $11^{\text {th }}$ ed., McGraw-Hill/Irwin, Boston, 2002.

2. Levine, David M., Berenson, Mark L., \& Stephan, David, Statistics for Managers Using Microsoft ${ }^{\circledR}$ Excel, Prentice Hall, Upper Saddle River, NJ, 1997.

3. Shannon, Patrick W., Groebner, David F., Fry, Phillip C., \& Smith, Kent D., A Course in Business Statistics, Prentice Hall, Upper Saddle River, NJ, 2002.

4. $\quad$ Keller, Gerald, \& Warrack, Brian, Statistics for Management and Economics, $5^{\text {th }}$ ed., Duxbury Press, Pacific Grove, 2000.

5. Shewhart, Walter A., Economic Control of Quality of Manufactured Product, D. Van Nostrand Company, Inc., New York, 1931.

6. Juran, J.M., Management of Quality Control, 1967 Course Notes, Visual Aid \#21.

7. Juran, J.M., and Gryna, Frank M., Jr., Quality Planning and Analysis, $2^{\text {nd }}$ ed., McGraw-Hill Book Co., NY, 1980, PP. 100-101, 127-128.

Notes 
Notes 